\title{
304 ステンレス鋼の応力腐食割れ伝播自動測定
}

\author{
高 野 道 典* \\ * 東北大学金属材料研究所
}

\author{
Automatic Measurement of a Crack Propagation Rate in \\ Stress Corrosion Cracking of Type 304 Stainless Steel \\ Michinori Takano* \\ * Research Institute for Iron Steel and Other Metals, Tohoku University
}

\begin{abstract}
An automatic measuring system of SCC crack propagation rate was developed. Crack length was obtained as a variation of an electric resistance of the specimen, in which the electric resistance was obtained from the voltage measurement under the constane current of $1 \mathrm{~A}$. Whole system for the measurement is composed of a personal computer system (PC-8801, PC-8049 N, PC-80 S 31, PC-8023 C), interface system ( $8255, \mathrm{ADC}$ ) and test machines (4 slow strain rate machines). A variation of electric resistance of an $1 \mathrm{~mm}$ thick Type 304 stainless steel exposed in air at room temperature without stress was within 0.5 micro-ohm. This corresponds to $30-40$ micro meter of crack length of the specimen. Stress corrosion test of Type 304 stainless steel was carried out in boilling $42 \% \mathrm{MgCl}_{2}$ solution by using a slow strain rate technique. The results showed a good agreement with those obtained in previous studies.
\end{abstract}

\section{1.まえがき}

各種環境下における材料の応力腐食割れ (SCC) 伝播 挙動を知ることは, 機構解明, 割れ寿命の予測あるいは 材料選定に対して重要である。

著者らはこれまで，SCC 伝播速度を知るために，電 気抵抗法 ${ }^{1)}$ あいは腐食セル外より顕微鏡観察によって,

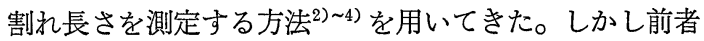
では精度の点で, また後者では測定者の労力の点で問題 があった。

最近測定器機の進歩が著しく, 精度のよい測定が可能 になって拈り，更にマイコンの普及により測定の自動化 が容易になっている。こうした背景を考慮して, 本報告 では, 304 ステンレス鋼の SCC 伝播挙動を, 電気抵抗 変化としてとらえ, 自動測定する方法を検討したので, その結果について述べる。

\section{2. 割れによる抵抗変化}

Fig. 1 に示すように, 長さ $l$, 幅 $W$, 厚さ $T$ の試験 片に長さ $X$, 幅 $l^{\prime}$ の割れが生じた場合を考える。試験 片及び環境の比抵抗值をそれぞれ $\rho$ 及び $\rho^{\prime}$ とすれば,

* 干980 仙台市片平 2-1-1 (2-1-1, Katahira, Sendai, 980 Japan)
抵抗值 $E R$ は平列抵抗体として

$$
E R=\frac{\rho l\left(\rho^{\prime} l^{\prime}+\rho l\right)}{\left\{(W-X)\left(\rho^{\prime} l^{\prime}+\rho l\right)+X \rho l\right\} T}
$$

で与劣らる。

割れ発生前の試験片抵抗值 SR は $X=0, l=0$ として

$$
S R=\rho l /(W T)
$$

となる。従って割れによる抵抗変化 $\Delta X R$ は (1) 式と

(2) 式の差で与えられる。

今, 環境の比抵抗值が試験片のそれに比べて大きいと すれば $\left(\rho^{\prime} \gg \rho\right), \Delta X R$ は

$$
\Delta X R=\frac{\rho l}{T}\left\{\frac{1}{W-X}-\frac{1}{W}\right\}
$$

で与えられる。

温度 $t$ における 304 ステンレス鋼の比抵抗值 $\rho$ は, $0.078 t+69.4(\mu \Omega)$ で与兄られる $T=0.1 \mathrm{~cm}, l=0.5 \mathrm{~cm}$ の試験片の $143^{\circ} \mathrm{C}$ (沸騰 $42 \%$ $\mathrm{MgCl}_{2}$ を想定）に拉ける割れ長さと抵抗值 $\left(R_{\mathrm{c}}\right)$ 及び抵 抗増 $\left(R_{\mathrm{c}}-R\right)$ の関係は (3) 式を用いて, Fig. 2 のよう に示される。割れが $5,000 \mu \mathrm{m}$ 進行すると，抵抗值は $193.7 \mu \Omega$ 増加することになる。抵抗増/割れ長さの比 は，割れ長さによって異なるが， $5,000 \mu \mathrm{m}$ までの範囲 では, $30 \sim 40 \mu \mathrm{m}$ の割れ進展に対して，ほぼ $1 \mu \Omega$ の抵 


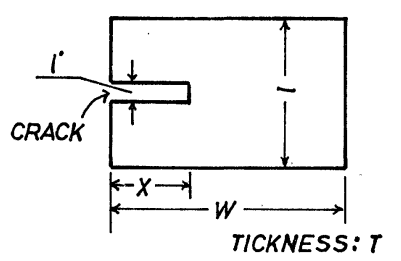

Fig. 1 Schematic illustration of a cracked specimen. $X$; crack length, $W$; specimen width, $l$; specimen length, $l$; ; crack width.

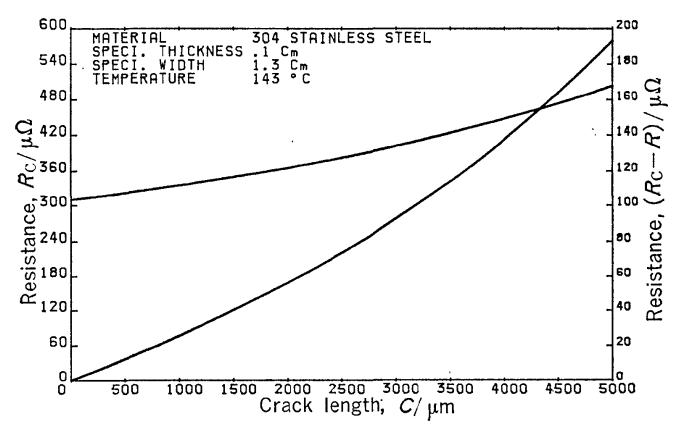

Fig. 2 Theoretical values of the electric resistance $R_{\mathrm{c}}$ and the increment of the resistance $\left(R_{\mathrm{c}}-\right.$ $R$ ) of the specimen with crack length $C$ (after eq. (3), $l=0.5 \mathrm{~cm}$ ).

抗增となる。

この結果を考慮して， $1 \mathrm{~A}$ の定電流に対して $0.5 \mu \mathrm{V}$ 以下の安定性をらるように装置を作製した。

\section{3. 装置の構成}

Fig. 3 飞装置の構成図を示す。パーソナルコンピュー (パソコン) は PC-8801 を用い, 周辺器機はプリンタ (PC-8023C)，ミニフロッピディスク (PC-80 S 31) 及び ディスプレイ (PC-8049N) である。

データを取り入れるための入出力装置 (I/O BOX) は メーカー (館城電子KK) に依頼し作製した。この I/O

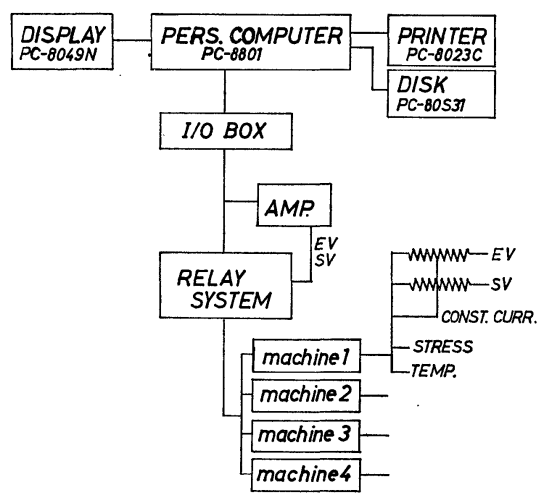

Fig. 3 Schematic diagram of the system used.

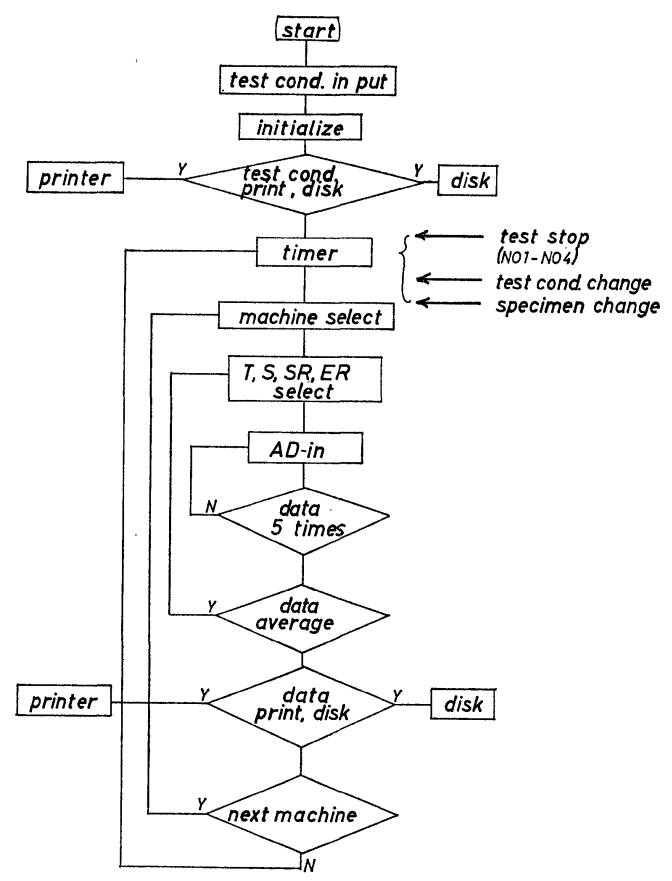

Fig. 4 Total flow chart of the system used.

BOX は, 2 ケの並列インターフェイス (8255), AD = ンバータ (MH 813, 12 ビット ADC) 及び定電流発生 装置から成る。 8255 によりりレーを作動させ，4台の SSRT (低ひずみ速度 SCC 試験機) 装置の中の所定の 1 台を選択する。SSRT 機が選択された後, 試験片の温 度 $(T)$, 応力 $(S)$, 標準電圧 $(S V)$, 割れによる電圧 $(E V)$ を読みとる。この場合, 定電流は SSRT 機が選択され た期間のみ流れる。精度を高めるためには, 高電流を付 与する方法が考兄られるが，腐食への影響を考光，本実 験では, $1 \mathrm{~A}$ 流した。

温度は, 銅ーニンスタンタン熱電対の起電力をそのま ま ADC に入力させて読みとった。

応力值は, 従来の記録入力側より, バッファアンプを 通して ADC に入力させた。また電圧測定には, 微小 直流電圧計（大倉電気 AM1001）を通して, ADC に入 カさせた。

\section{4. 測定プログラム}

Fig. 4 亿測定用プログラムのフロチャートを示す。 プログラムスタート後, 実験条件を入力する。これは, テスト番号, 日付け, 材料, 環境, クロスヘッド速度 (CS), 測定時間間隔, その時間内にいくらの抵抗増があ ればデータにするか, 最終割れ長さ（あるいは応力, の び，時間）などである。

パソコンを初期化した後, タイマーが作動する。所定 の時間になれば, SSRT 機を選択し, $T, S, S R$ 及び 
$E R$ をそれぞれ 5 回読み，最大值と最小值を除いた 3 ケ の平均值をデータにする。抵抗增 $(E R-S R)$ が所定の值 に達していなければ, データは無視される。しかしこの 場合でも応力值をプロットするため, $0.01 \mathrm{~mm} / \mathrm{min}<$ CS では 30 分ごとに，またそれ以下の CS では 1 時間 ごとにデータを入力するようにした。1 回の測定にはほ ぼ $20 \mathrm{sec}$ を要する。

PC-8801 では FUNCTION KEY あるいは HELP KEY を用いることによって，プログラム実行中でも， 割り込みが可能である。これらの KEYを利用して試験 中でも, 実験条件を变更したり, 試料のとり変えが可能 である。

\section{5. 測定結果}

\section{1 実 験方法}

試料として市販の 304 ステンレス鋼 $(18.0 \% \mathrm{Cr}$, $8.40 \% \mathrm{Ni}, 0.056 \% \mathrm{C}, 0.64 \% \mathrm{Si}, 0.96 \% \mathrm{Mn}$, Fe bal.) を用いた。

試験片の模式図を Fig. 5 に示す。

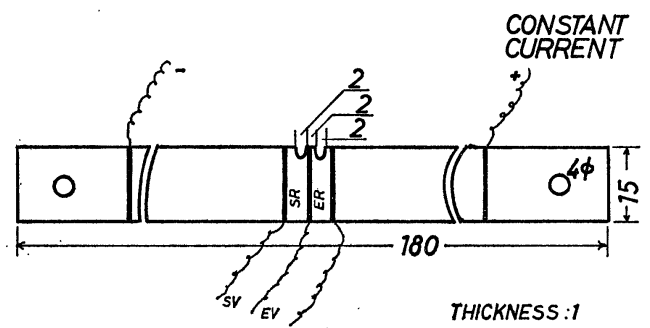

Fig. 5 Schematic illustration of the test specimen.

試験片には二つの丸底ノッチを付し，一方は試験片の 塑性変形あるいは温度変化による抵抗変化分を補償する ための標準抵抗部 (SR) である。この $\mathrm{SR}$ 部及び 3 本の リード線 $(0.2 \mathrm{~mm} \phi$ 銅線) はシリコン系塗料で被覆し た。割れは $E R$ 部のノッチ底から発生する。

溶液は 304 ステンレス鋼が SCC を起こしやすい $42 \% \mathrm{MgCl}_{2}\left(143^{\circ} \mathrm{C}\right)$ を選んだ。

\section{2 測定精度}

試験片を無負荷で, 常温空気中に放置した場合の抵抗 值 $(S R, E R)$ を Table 1 飞示す。ER-SR の值はほぼ $135 \pm 0.5 \mu \Omega$ の範囲にある。従って前述の割れ長さ一抵抗 值の関係から, 理論的には $30 \mu \mathrm{m}$ 程度の誤差で測定が 可能であることがわかる。(本試験片の場合, 装置の特 性から $S R / 8$ または $E R / 8$ が $1 \mu \Omega$ となっている)。

\section{3 測 定結果}

Fig. 6 K $42 \% \mathrm{MgCl}_{2}\left(143 \%{ }^{\circ} \mathrm{C}\right)$ 中, $0.0009 \mathrm{~mm} /$ $\min$ のクロスヘッド速度で試験を行った場合の応力及 び抵抗值 $(E R-S R)$ と時間（あるいはのび）の関係を示 す。抵抗值が急增し始めると応力值の勾配が減少し始め
Table 1 The results of stability test of the system for the electric resistance measurement.

\begin{tabular}{|c|c|c|c|c|c|c|c|c|c|c|}
\hline & SR & & ER & & $\begin{array}{c}E R-S R \\
(\mathrm{micro} V)\end{array}$ & $i$ & CLOCK & $\begin{array}{l}1 \\
1\end{array}$ & TIME & \\
\hline 1 & 1426 & l & 2508 & $i$ & 135.8 & I & $18: 13: 31$ & 1 & $0: 1$ & \\
\hline 1 & 1419 & i & 2499 & 1 & 135.0 & i & $19: 13: 02$ & 1 & $1: 0$ & \\
\hline 1 & 1421 & i & 2499 & 1 & 134.8 & 1 & $20: 13: 03$ & 1 & $2: 0$ & \\
\hline I & 1422 & 1 & 2502 & 1 & 135.0 & 1 & $20: 43: 04$ & 1 & $2: 30$ & \\
\hline I & 1421 & 1 & 2499 & 1 & 134.7 & 1 & $21: 13: 04$ & 1 & $3: 0$ & I \\
\hline I & 1422 & 1 & 2500 & 1. & 134.8 & 1 & $21: 43: 05$ & 1 & $3: 30$ & I \\
\hline I & 1420 & I & 2497 & 1 & 134.6 & 1 & $22: 13: 03$ & 1 & $4: 0$ & 1 \\
\hline 1 & 1422 & 1 & 2502 & 1 & 135.0 & 1 & $22: 43: 02$ & 1 & $4: 30$ & \\
\hline I & 1421 & 1 & 2500 & 1 & 134.8 & 1 & $23: 13: 04$ & 1 & $5: 0$ & \\
\hline I & 1423 & 1 & 2503 & 1 & 135.0 & 1 & $23: 43: 03$ & 1 & $5: 30$ & \\
\hline I & 1424 & 1 & 2503 & 1 & 135.0 & 1 & $00: 12: 04$ & 1 & $6: 0$ & \\
\hline I & 1423 & 1. & 2505 & 1 & 135.3 & 1 & $00: 43: 04$ & 1 & $6: 30$ & \\
\hline 1 & 1422 & 1 & 2503 & 1 & 135.2 & 1 & $01: 13: 03$ & 1 & $7: 0$ & \\
\hline 1 & 1423 & 1 & 2503 & 1 & 135.1 & 1 & $02: 13: 03$ & 1 & $8: 0$ & \\
\hline 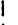 & 1424 & 1 & 2506 & 1 & 135.3 & 1 & $02: 43: 04$ & 1 & $8: 30$ & \\
\hline 1 & 1423 & I & 2504 & 1 & 135. 1 & 1 & $03: 13: 05$ & I & $9: 0$ & \\
\hline I & 1424 & 1 & 2505 & 1 & 135.0 & 1 & $04: 13: 04$ & 1 & 10: 0 & \\
\hline 1 & 1423 & 1 & 2504 & 1 & 135.1 & 1 & $04: 43: 04$ & 1 & $10: 30$ & \\
\hline & 1424 & I & 2506 & 1 & 135.2 & 1 & $05: 13: 04$ & 1 & $11: 0$ & \\
\hline I & 1424 & 1 & 2506 & 1 & 135.3 & 1 & $05: 43: 03$ & 1 & $11: 30$ & \\
\hline & 1426 & 1 & 2508 & 1 & 135.3 & 1 & $06: 13: 04$ & 1 & $12: 0$ & \\
\hline & 1425 & & 2508 & 1 & 135.3 & 1 & $06: 43: 03$ & 1 & $12: 30$ & \\
\hline & 1426 & & 2509 & 1 & 135.4 & 1 & $07: 13: 04$ & 1 & 13: 0 & \\
\hline & 1425 & & 2509 & 1 & 135.5 & 1 & $07: 43: 04$ & 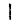 & $13: 30$ & \\
\hline & 1426 & & 2509 & 1 & 135.4 & 1 & $08: 13: 04$ & 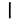 & $14: 0$ & \\
\hline & 1425 & & 2508 & 1 & 135.4 & 1 & $08: 43: 05$ & & $14: 30$ & \\
\hline
\end{tabular}

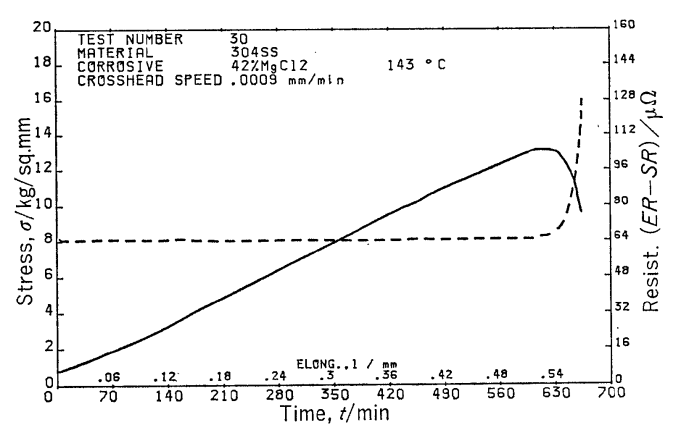

Fig. 6 Dependence of the stress (solid) and the electric resistance (broken) upon the test time (or elongation).

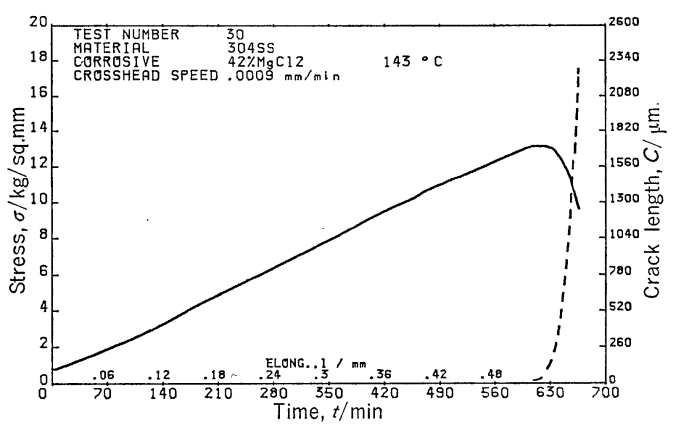

Fig. 7 Dependence of the stress (solid) and the crack length (broken) upon the test time (or elongation).

最大値に達することがわかる。

（3）式を用いて割れ長さを求めた結果を Fig. 7 亿示 す。また割れ伝播速度を Fig. 8 に示す。これらの図で 


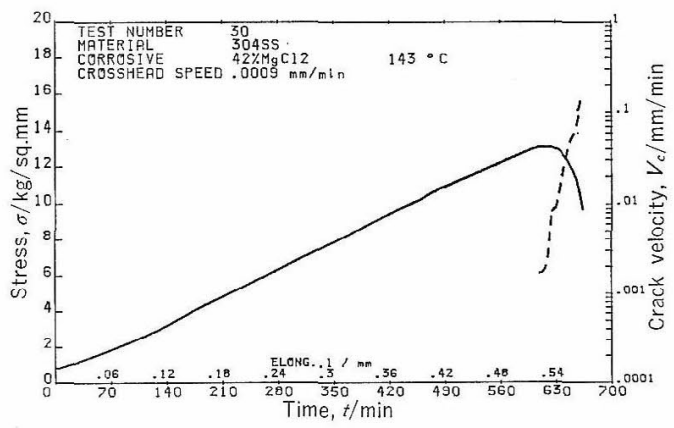

Fig. 8 Dependence of the stress (solid) and the crack velocity (broken) upon the test time (or elongation).

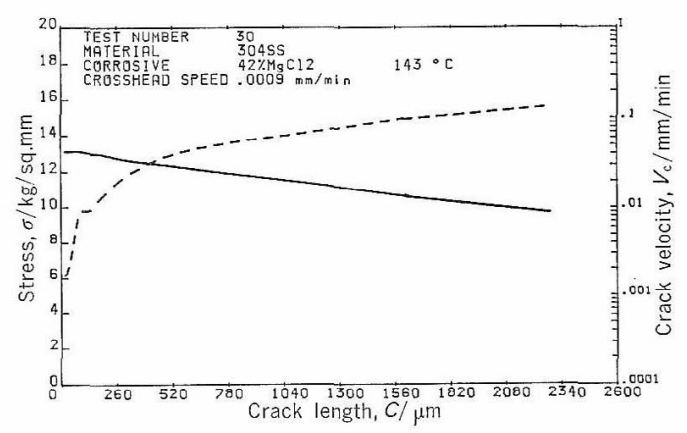

Fig. 9 Dependence of the stress (solid) and the crack velocity (broken) upon the crack length.

はいずれも応力值との関係をみるため，その值も図示し た。

Fig. 8 に六られるように, 割机伝播速度 $V_{\mathrm{c}}$ は時間 と共に增加して怙り，従来の結果 $\left.{ }^{2}\right)$ 同じ傾向を示して いる。な私本実験の場合 $V_{\mathrm{c}}<0.0001 \mathrm{~mm} / \mathrm{min}$ の值は無 視してデータ整理を行った。

Fig. 9 に応力及び割れ伝播速度之割れ長さ之の関係 を示す。図では明確でないが，割れ長さが 17 83 $\mu \mathrm{m}$ の範囲で応力は最大值 $\left(13.1 \mathrm{~kg} \cdot \mathrm{mm}^{-2}\right)$ を示し，先の後 割れの進行々共に応力は減少している。また割れの成長 と共に割れ伝播速度が一定値に近づくことる從来の結 果 ${ }^{3)}$ と一致している。

クロスヘッド速度が $0.002 \mathrm{~mm} / \mathrm{min}$ で試験を行った 結果を Fig. 10 及び Fig. 11 に示す。この場合は応力 が最大值を過ぎた点 (Fig. 10 の矢印) で $C S=0$ にして いる。外部からの変形速度を０にすると割れ長さの勾配 は小さくなり (Fig. 10)，李た割れ伝播速度もFig. 9 の 場合と違って，減少することがわかる。(Fig. 11)。

以上 TEST No. 30 及び 10 のいずれの場合も割饥 長さが $2,000 \mu \mathrm{m}$ 《達したら試験を停止するように入力

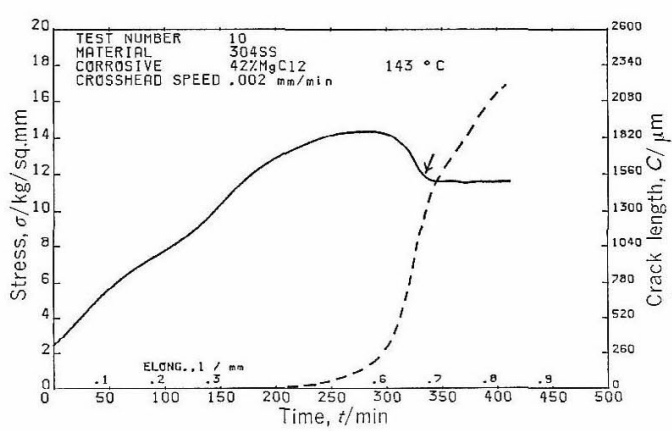

Fig. 10 Dependence of the stress (solid) and the crack length (broken) upon the test time (or elongation).

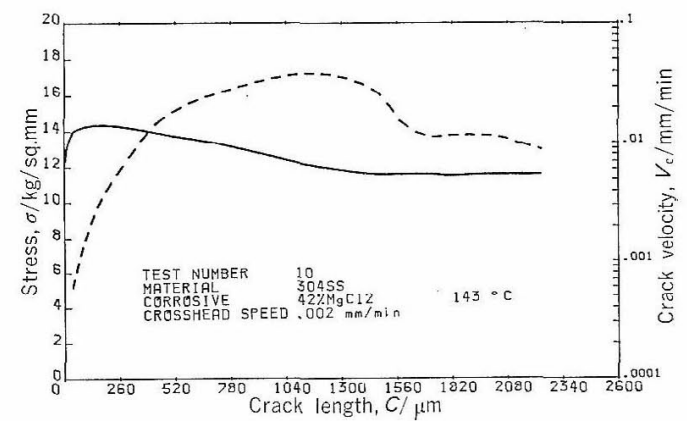

Fig. 11 Dependence of the stress (solid) and the crack velocity (broken) upon the crack length.

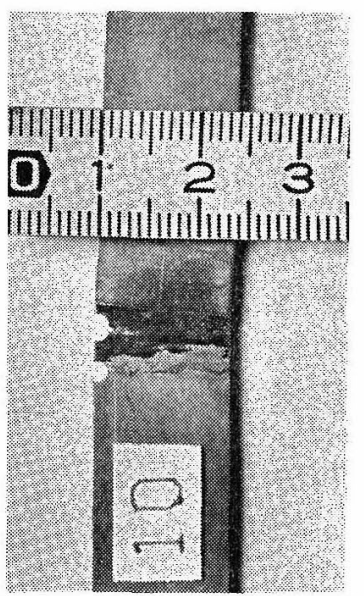

Fig. 12 Photograph of the specimen (test No. 10) after SCC test.

したものである。しかしいずれの場合も割れ長さがこの 值を少し過ぎている (No. 30, 10 でそれぞれ 2,280 $\mathrm{m}$ ， $2,247 \mu \mathrm{m})$ ，これは測定間隔 $5 \mathrm{~min}$ の実験で，最後の 5 min で $2,000 \mu \mathrm{m}$ を過ぎたためである。

Fig. 12 は No. 10 の試験後の試験片表面写真である。 
写真から明らかなように, 割れはほぼ $2,000 \mu \mathrm{m}$ で停止 している。(本方法では，貫通割れが検出され，浅い表 面割れは測定できない。

な特，測定時に試験片に $1 \mathrm{~A}$ の定電流を流すことに よって, SCC 過程に何らかの影響があることが媳念さ れた。従って本実験と同一条件（電流のみ流さない）で 試験を行った結果, 最大応力值はほぼ同じ值が兄られ た。

\section{6. まとめ}

（1）パーソナルコンピュータを用いて，応力腐食割 れ伝播自動測定装置を開発した。

(2) 割れ長さは, 定電流 $(1 \mathrm{~A})$ 下で標準抵抗との差 を求めることにより測定した。

（3）測定の精度は $30 \mu \mathrm{m}$ 程度である。
(4) 304 ステンレス鋼の $42 \% \mathrm{MgCl}_{2}\left(143^{\circ} \mathrm{C}\right)$ 中の 割れ伝播挙動は, 従来の報告と同じ傾向を示した。

（5）定電流を流すことによる腐食への影響は，大き くないことが明からにされた。

(Received May 18, 1984)

\section{文献}

1）川鴆朝日, 高野道典, 下平三郎：日本金属学会 誌, 31, 1089 (1967).

2) 寺本和啓, 高野道典：日本金属学会誌， 43,744 (1979).

3) 中山武典: 学位論文 (東北大学), 1982.

4) 高野道典, 永田達也: 防食技術, 32, 456 (1983).

5）金属データブック，日本金属学会編，丸善，p. 105 (1974). 